\title{
Thermo-dynamical modelisation of the degradation of a ball bearing in variables use conditions
}

\author{
Dalila Belmiloud ${ }^{1,2,}{ }^{*}$, Mohammed Lachi ${ }^{1}$, Hervé Pron ${ }^{1}$, Fabrice Bolaers ${ }^{1}$, Jean-Paul Dron ${ }^{1}$, \\ Xavier Chiementin ${ }^{1}$, and Ali Laggoun ${ }^{3}$ \\ ${ }^{1}$ GRESPI, LTM Laboratory, Reims Champagne Ardenne University, 51687 Reims, France \\ ${ }^{2}$ LDMV, MI Département, Faculté des Sciences de l'Ingénieur, 3500 Boumerdes, Algeria \\ ${ }^{3}$ UR-MPE Laboratory, Boumerdes University, 3500 Boumerdes, Algeria
}

Received: 2 April 2018 / Accepted: 11 September 2020

\begin{abstract}
Many sources of heat can emanate from the operation of a rotating machine, and one of which is the friction among the different parts of the ball bearings. Over time, these frictions may lead to a tearing of matter of the rings or on the rolling elements that cause some type of degradation by flaking. Flaking, in turn, produces a repetitive shock as a new source of thermal energy. This work proposes a physical model for the study of the thermal heating of a ball bearing during operation. The resolution of the energy balance is achieved by the Nodal method where both the heating due to friction and the heat induced by the passage of the balls on defect are taken into account. The proposed thermal model is validated through an experimental thermal analysis. The obtained results show that the temperature increases in the position of defect ball ring with increasing rotational speed. The same results are obtained for the influence of radial load.
\end{abstract}

Keywords: Ball bearing / thermal analysis / defect ball bearing / bearing thermal behavior / infrared thermography

\section{Introduction}

In rotating machinery such as motors and mechanical transmission, ball bearings are extensively used. This is often justified by their good performance, associated with the significance of their maximum load. Incidents caused by undetected defects in the operation of this component can have very serious consequences on both safety and maintenance. A number of studies, [1-4], have been devoted to the detection of bearing failure and some methods based on acoustic and vibration analyses have been developed to predict the life cycle of a bearing. Abnormal levels of temperature rise remain a very effective way to detect failure in a bearing. Generally, when two surfaces are moving, it appears inevitably a heat generation at the contact. In the literature on bearing problems, two types of heat transfer exchanges are reported: (i) heat conduction between different rolling elements such as the inner ring, the rolling elements, the outer ring and (ii) thermal effects mainly due to different

\footnotetext{
* e-mail: belmilouddalila@yahoo.fr
}

heat fluxes generated and which affect the bearing lifespan.

- Conduction heat transfer between the different rolling elements is based on the principle of thermal contact on the rolling elements. The fundamental aspects of thermal rolling contact were highlighted by Bejan [5]. The rolling elements contacts situated on rings forces the heat flux lines to concentrate on the contact area. This concept of macro constriction was studied by Holm [6] and the one of static constriction was established by Chow and Yovanovich [7] who studied the heat transfer in a given geometry of contacts. Further this theory was performed by Lemczyk and Yovanovich [8] where they introduces the use of the Biot number to characterize the heart exchange. This constriction thermal resistance was generalized to a dynamic resistance constriction model that takes into account the rotation of the elements on each other. Their model is based on the Hertz theory in case of statics and smooth contacts which tends to increase thermal conductance with movement of the elements in contacts.

- Heat generated by the normal operation of a structure has been the object of a number of studies aimed at evaluating the constraints associated with heat flux and as 
a result predicting fatigue and bearings lifespan. Sliding effects (friction effect) was originally analyzed by Jones [9] and further investigated by Harris [10]. The latter uses the Hertz theory for calculating contact areas between bearing elements, and determines a relation of heat flux generated by friction in the presence of a lubricant. He then uses a nodal model to determine temperature distribution in the rolling elements and subsequently, in the structure. Liao and Lin [11] investigated the case of the overheating of ball bearings at high speed. They determined contact angles and surfaces when the bearing is overheated, i.e. when elements dilate and thus, the performance of ball bearing is evaluated. Böhmer et al. [12] demonstrated the influence of the generated heat flux by friction on the fatigue behavior of a ball bearing. Muzychka and Yovanovitch [13] built their research on Blok's findings [14] to estimate the contact resistance associated with maximum temperature in case of an elliptical contact. They set another thermal resistance formula; nevertheless, they noted that this approach is only valid for a relatively high Peclet number. Baïri et al. [15] investigated the stationary thermal behaviour of a ball bearing and they established a thermal map of the ball bearing, the flash and the average temperature of the heated region. In Reference [16], Pouly et al. developed a thermal network model to evaluated power loss attributed to rolling friction and sliding friction between balls and cage during the movement. In their model, the resistance between balls and oil, the ball and cage drag as well as hydrodynamic forces are considered. They analysed too the influence of an air-oil mixture in rolling bearing on the thermal behaviour of rolling bearing elements operating at high speed. Yan et al. [17] showed that the presence of the cage affects significantly air-oil flow and heat dissipation within the bearing cavity. Takabi and Khonsari [18] developed a theoretical model to study the temperature of the ball bearing, considering several parameters like heat transfer mechanism, frictional heat generation, preload and thermal response of the system. Neurouth et al. [19] developed two models of grease lubricated thrust ball bearing using thermal network model to predict the power loss and heat transfer with lubricant taking into account different assumptions. The obtained numerical results showed that grease and air-oil mixture do not have any significant role on thermal transfer in the bearing. A third thermal model, which takes into the account rings, balls and contact areas, was proposed. Takabi and Khonsari [20,21] developed a dynamic simulation of rolling bearing thermal failure that considers the thermal expansion. In this case two types of failure were investigated for a deep groove ball bearing rotating at high speed with a large radial load. The results show that the unstable motion of the cage induces a seizure in the bearing. For cylindrical roller bearing used in high speed machine tools, thermal failure is due to thermal preload, which affect lubricant film thickness and causes a thermal seizure. Neurouth et al. [22] proposed a thermo-mechanical model of the FZG test rig based on the thermal network method. The results show that the inner and outer rings of a rolling bearing are at different temperatures. In this study, two approaches were proposed to investigate the thermal behaviour of rolling bearing elements. Yan et al. [23] developed a transient thermal network model of a spindle bearing system, which consider the thermal behaviour and the structure interactions. The temperature rise of the outer ring as a function of rotational speed using, is obtained in steady and transient regime. The obtained results was discussed and compared to the experimental ones. Zheng and Chen [24] proposed a multi-node thermal network model for an angular ball bearing to study the heat generation and the thermal transfer in bearings, while taking into consideration, the presence of the coolant lubricant, and the radial and axial structural constraints.

However, it has to be mentioned that no model in the literature accounts for the case of heat flow related to the presence of defect on bearing tracks. Indeed, this impact results in a tearing off of the material attributed to a plastic transformation, which amounts to heat dissipation at this point. In this context, the number of parameters relevant to heat transfer is important, and among these parameters, we can list rotational speed, load, lubrication, various frictions (rolling elements, rings, cages) and bearing failure.

Thus, the objective of this work is to determine the temperature field generated not only by the heating of the bearing by friction alone but also by the effect of the presence of a defect on the bearing (in our case the defect is located on the outer ring). The proposed model allows obtaining a direct correlation between the severity of the defect and temperature variation of the structure studied via a comprehensive equation that links all the parameters of the system. The model permits to determine the severity of the damage via thermal measurements.

In this work, the thermal model allows the determination of the temperature field in the presence of a defect. The final resolution is based on the nodal method.

\section{Thermal modeling}

In this study, we present a heat transfer model to simulate, in a steady state regime, the temperature distribution in the ball bearings, with and without defect, operating at moderate speed. The system as represented in Figure 1 is divided into isothermal elements designated as nodes, which are interconnected by their thermal resistances. These resistances are generally dependent on a heat transfer mechanisms in the bearing: conduction, free convection, forced convection and radiation. However, the contribution of radiation heat transfer is assumed very small with respect to fluid convection and conduction between elements. Such as that sketched in Figures 1 and 2, the modeled system is made up of a house, inner ring, outer ring, balls, cage and shaft. A small amount of grease is used as a lubricant between the balls and the cage and the system is surrounded by air (Fig. 2). We have used 21 nodes 


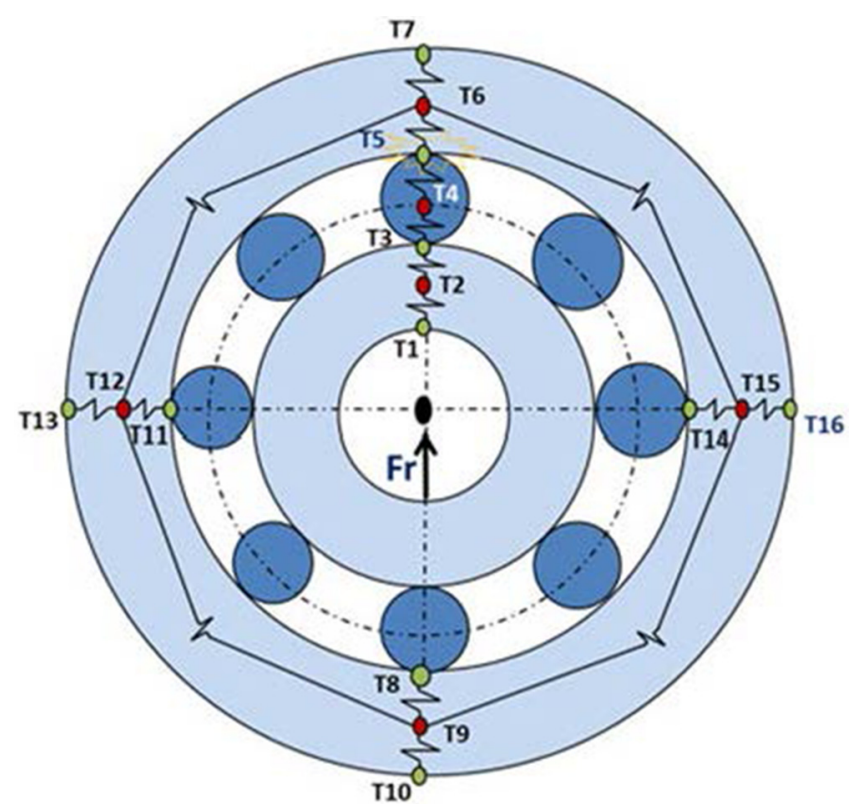

Fig. 1. Node distribution in the ball bearing.

in our system. The nodes T11, T12 and T13 are symmetrical to the nodes T14, T15 and T16.

\subsection{Nodal distribution}

The discretization of the system components, ball bearing, shaft and housing is shown in Figures 1 and 2 . On the shaft are placed three volumetric nodes: (i) at the free end of the shaft, (ii) in middle, (iii) at the other end of the shaft. This modelling, coupled with that of the bearing obtained in a previous section, results in a $21 \times 21$ square system, whose resolution gives the temperature field in the bearing.

The housing, shaft, grease and air temperatures are considered as input parameters and determined from experimental data. Load direction is tested to investigate the effect of the loaded part on temperature rise of the system. Different loads are then used in a series of experiments to investigate the effect of rotation speed on temperature rise.

The formulae used to calculate thermal resistances are given below.

\subsection{Thermal resistance of conduction}

The outer and inner rings are considered as two cylinders and the thermal resistance is given by:

$$
R_{t h k}=\frac{1}{2 \pi K L} \ln \left(\frac{d_{e x t}}{d_{i n t}}\right)
$$

with $K$ is the thermal conductivity

$$
K=46(W / m K)
$$

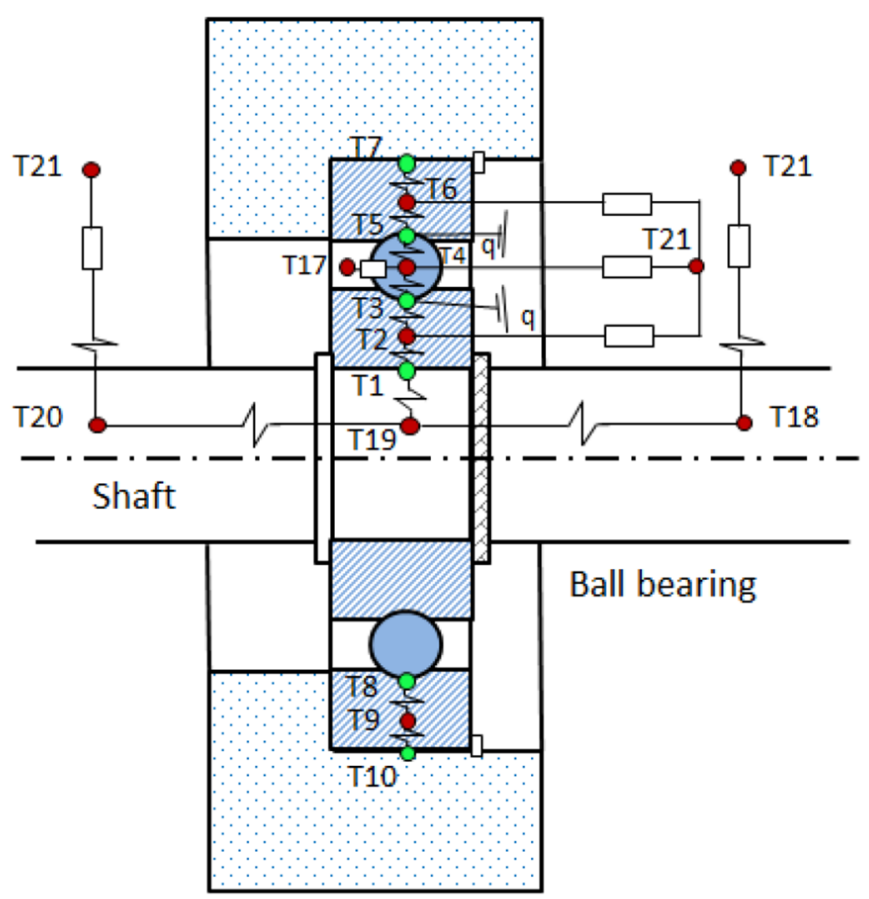

Fig. 2. Thermal network elements.

\subsection{Thermal resistance of constriction heat transfer}

As explained in the introduction, because of the constriction phenomenon, the source of heat generated by friction is concentrated on a very small contact area. As a result, and following this model, one node is placed on the surface whereas another is in the bulk [25], and then connected by a constriction resistance as detailed by Muzychka and Yovanovitch [13]. Thermal constriction resistance is:

$$
R_{t h}=\frac{0.918}{2 b \chi \sqrt{2 a V}}
$$

\subsection{Heat exchange coefficient by convection heat transfer}

Convection heat transfer between the ball bearing and the surrounding air or between the ball bearing and the lubricant is difficult to quantify. For each forced convection process, thermal resistance is estimated after the average Nusselt number was determined. The expression of convection thermal resistance is given by the following expression:

$$
R_{t h V}=\frac{1}{h_{v} \cdot s}=\frac{1}{s}\left(\frac{L}{K N u}\right)
$$

Where $s$ : exchange heat surface $\left[\mathrm{m}^{2}\right]$

$N u$ : Nusselt number

$h_{v}$ : Convection heat transfer coefficient $\left[\mathrm{w} / \mathrm{m}^{2} . \mathrm{K}\right]$ 


\subsection{Natural convection heat transfer between the outer ring and the ambient atmosphere}

In the case where the heat flux is generated by convection, we use Newton law given by:

$$
H_{c}=h_{v} . s . \Delta T
$$

In stable air conditions, the convection heat transfer coefficient between the ball bearing surface and the atmosphere as estimated by Jeng and Huang [26] is given by:

$$
h_{v}=2.310^{-5}\left(T-T_{a}\right)^{0.25}
$$

$T_{a}$ : the air temperature.

Palmgren [27] proposed for the outer ring surface as follows:

$$
s=\pi D_{h}\left(W_{h}+\frac{1}{2} D_{h}\right)
$$

$D_{h}$ : diameter of the outer ring of the ball bearing

$W_{h}$ : width of the outer ring of ball bearing

From Equations (4) and (5) it follows that the heat flux is given by:

$$
H_{c}=2.310^{-5} \cdot \pi D_{h}\left(W_{h}+\frac{1}{2} D_{h}\right) \cdot\left(T-T_{a}\right)^{1.25}
$$

\subsection{Forced convection heat transfer between the inner ring and compressed air flow}

The rotation of the inner ring in contact with the outside atmosphere induces a forced convection heat transfer with the surrounding air. For a disc in rotation, Wagner [28] proposed the average Nusselt number as follows:

$$
\begin{array}{llll}
N u=0.4 R_{e}^{1 / 2} \operatorname{Pr}^{1 / 3} & \text { for } & R e<2.510^{5} \\
N u=0.0238 R_{e}^{0.8} \operatorname{Pr}^{0.6} & \text { for } & R e>3.210^{5}
\end{array}
$$

with $\operatorname{Pr}=0.71$ for the air.

\subsection{Convection heat transfer in presence of grease}

For use of a small amount of grease as a lubricant Using a small amount of grease as a lubricant, Neurouth et al. [19] evaluated the convection heat transfer coefficient with Nusselt number expressions as follows:

$$
\begin{gathered}
N u=0.332 \operatorname{Re}^{1 / 2} \operatorname{Pr}^{1 / 3} \text { for } \quad\left\{\begin{array}{l}
10^{3}<R e<5.10^{5} \\
\operatorname{Pr}>0.5
\end{array}\right. \\
N u=0.028 \operatorname{Re}^{4 / 5} \operatorname{Pr}^{1 / 3} \quad \text { for } \quad\left\{\begin{array}{l}
5.10^{5}<R e \\
\operatorname{Pr}>0.5
\end{array}\right.
\end{gathered}
$$

With

$$
\begin{gathered}
R e=\frac{V_{c} \times L}{v} \\
\operatorname{Pr}=\frac{v_{0}}{\alpha} \\
\operatorname{Pr}=10400 \\
\alpha=4.33 \times 10^{-3}\left(\mathrm{~m}^{2} / \mathrm{s}\right) \\
\rho=998\left(\mathrm{~kg} / \mathrm{m}^{3}\right)
\end{gathered}
$$

\section{Heat Generation}

Thermal and mechanical processes in a motion system, especially in bearings systems are coupled and all generated heat must be taken into account. This part deals with the mechanical effects that can generate heat.

In our case, two sources of heat generation are considered and the first, which is the most common, corresponds to the heat generated by frictional effects: inner ring/ball friction (Q1) and outer ring/ball friction (Q2). The second is due to impact of balls on the defect seen on the bearing, which has not been studied in other works: heat generated by the impact of ball on a defect seen on the bearing (Q3); hence, the originality of this presented work.

To calculate power losses due to frictions at the different points of contact: inner ring/ball and outer ring/ ball, it is necessary to carry out kinetic calculations, which allows to obtain the velocity and forces to be integrated in the model. The grease is used to avoid dry friction between the elements, in our case, we assume that the grease has no influence on friction power loss and the slip between ball bearings and the raceway is negligible.

\subsection{Bearing frictional power loss}

The bearing frictional power loss is expressed by the product of speed by the friction torque as detailed by Harris [10].

$$
Q_{\text {roul }}=1.047 \times 10^{-4} \omega_{\text {roul }} M_{f r}
$$

The friction torque includes, torque due to applied load $M_{1}$, viscous friction torque $M_{v}$ and torque due to the flange $M_{f}$, Palamgren [30] proposed a formula to calculate the viscous friction torque as follows:

$$
\begin{gathered}
M_{f r}=M_{l}+M_{v}+M_{f} \\
M_{1}=f_{1} F_{\beta} d_{m} \\
\left\{\begin{array}{lr}
M_{v}=10^{-7} f_{0}\left(v \omega_{\text {roul }}\right)^{2 / 3} d_{m}^{3} & \text { for } \quad v . \omega_{\text {roul }} \geq 2000 \\
M_{v}=160.10^{-7} f_{0} d_{m}^{3} & \text { for } \quad v . \omega_{\text {roul }}<2000
\end{array}\right.
\end{gathered}
$$

In this study, we have $M_{f}=0$. 


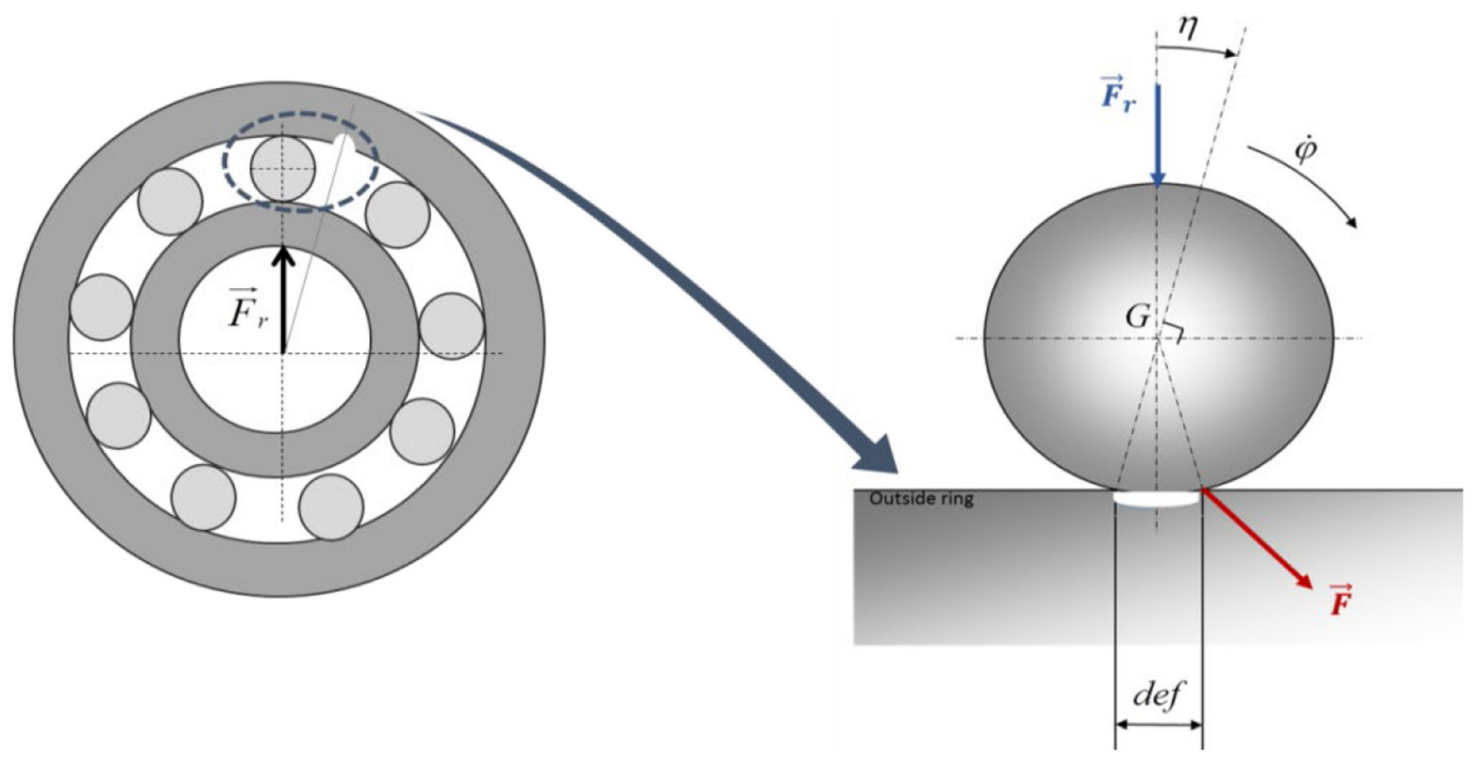

Fig. 3. Representation of the impact region in ball bearing.

\subsection{Heat source generated by defect}

A second large family of heat sources can be considered in bearings with defect, attributable to the impacts between the rolling elements and the singularity generated on the raceway. This type of distribution necessitates first of all a modeling of the defect, which is represented by a hole in the outer ring material (Fig. 3). The singularities are the source of impact during the passage of the rolling elements, and the repeated impacts exert a pull on the material, thereby resulting in a plastic deformation.

The force exerted by a rolling element $F_{m}$ on the singularity can be expressed in different ways, depending on the assumptions. The most common form is the one proposed by Tandon and Choudhury [29]: the shape of the excitation signal is considered to be a combination of three signals having triangular, rectangular and semi sinusoidal forms. Bogard et al. [30] have shown that the proposed three forms of the signal separately give similar results. Thereby, we consider the form of the signal to be triangular (Fig. 4).

In this case, the defect model is based on these assumptions:

- When a ball passes the location of a defect in outer ring, the exciting forces expressed by the amplitude $\mathrm{A}$, is precisely equal to the forces acting on the ball.

- The rotational speed of the center of the ball is constant.

- The defect is symmetrical about a radius of the bearing.

- The sliding phenomenon is ignored.

- The rebound phenomenon due to the shock is ignored.

For the static problem, the rotational speed of the center of the ball is expressed as:

$$
V_{c b}=\frac{2 a}{\Delta T_{s}}=\frac{D_{1}}{T_{d o}}
$$

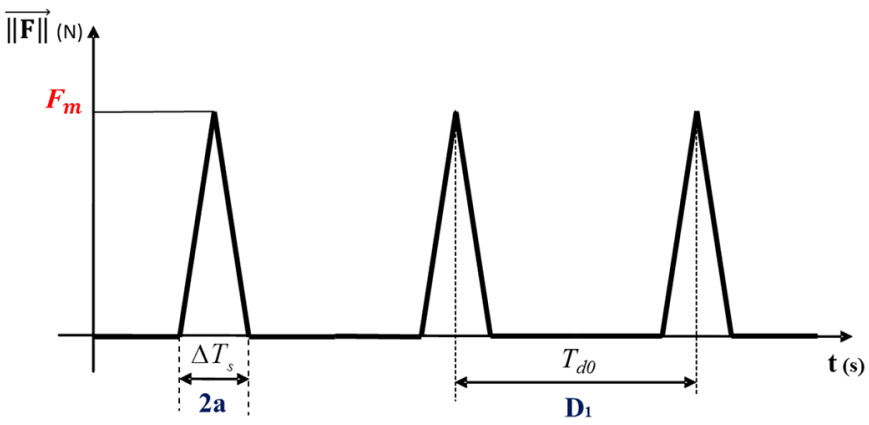

Fig. 4. Form of the excitation signal.

a: the half radius of the defect in the rolling direction, $\Delta T_{s}$ : The shock period

$D_{1}$ : the distance between the middle of two balls

$T_{d o}$ : the periodicity of the passage of rolling elements upon the outer ring defect.

The shock period is given by:

$$
\begin{gathered}
\Delta T_{s}=\frac{2 a T_{d o}}{D_{1}} \\
D_{1}=\frac{2 \pi r_{m}}{Z}
\end{gathered}
$$

Therefore

$$
\Delta T_{s}=\frac{2 a T_{d o} Z}{2 \pi r_{m}}
$$

The defect situated on the outer ring of the ball bearing is revealed by its characteristic frequency, which is equal to 
the inverse of the characteristic period given as:

$$
T_{d o}=\frac{1}{f_{d 0}}=\frac{2}{f_{r} Z\left[1-\left(\frac{d}{D} \cos \alpha\right)\right]}
$$

Equation (17) is substituted in Equation (18) and the shock period can thus be written as:

$$
\Delta T_{s}=\frac{2 a}{\pi r_{m} f_{r}\left[1-\left(\frac{d}{D} \cos \alpha\right)\right]}
$$

Therefore, the power of the shock is expressed as follows:

$$
P_{s}=\frac{2 a F_{m}}{\Delta T_{s}}
$$

From Equations (19) and (20), the power of the shock is stated as:

$$
P_{s}=\pi r_{m} F_{m} f_{r}\left[1-\left(\frac{d}{D} \cos \alpha\right)\right]
$$

According to the previous assumptions, the external excitation force or the pulse amplitude generated each time the rolling element strikes the defect on the raceway of the outer ring, is equal to the forces acting on the ball.

Replacing $F_{m}$ by $Q_{\max }$ in Equation (21) we obtained:

$$
P_{s}=\pi r_{m} f_{r} Q_{\max }\left[1-\left(\frac{d}{D} \cos \alpha\right)\right]
$$

Using Steinbeck's formula for ball bearings under pure radial load and nominal diametrical clearance, defined as:

$$
\begin{gathered}
Q_{\max }=\frac{5 F_{r}}{Z \cos \alpha} \\
P_{s}=\frac{5 \pi r_{m} f_{r} F_{r}}{Z \cos \alpha}\left[1-\left(\frac{d}{D} \cos \alpha\right)\right]
\end{gathered}
$$

The incident heat flux density is expressed as:

$$
\Psi_{d o}=\frac{P_{s}}{S_{d}}
$$

With

$$
S_{d}=\pi a b
$$

Then from Equations (24)-(26), we obtained:

$$
\Psi_{d o}=\frac{5 \cdot F_{r} \cdot \omega \cdot r_{m}}{2 \cdot \pi \cdot a \cdot b \cdot N \cdot \cos \varphi}\left[1-\left(\frac{d}{D}\right) \cos \varphi\right]
$$

\section{Numerical resolution}

The first law of thermodynamics for a closed system is expressed [31] by this equation:

$$
Q=W+\frac{d u}{\mathrm{~d} t}
$$

where $Q$ represents the heat transfer rate expressed in (W) taken as positive when it enters in the system, $W$ is the work transfer rate expressed in $(\mathrm{J} / \mathrm{s})$ and $u$ is the internal energy variation with time, $t$, in $(\mathrm{J} / \mathrm{s})$.

Changenet et al. [31] rely on the following analysis: the work rate is substituted by the transferred heat from the system to the other elements and the rate of internal energy is substituted by the rate of absorbs heat (thermal inertia). Then, the equation (28) can be written as in referense [31]:

$$
\begin{gathered}
Q_{i}=\sum_{j, j \neq i}^{n} \frac{\left(T_{i}-T_{j}\right)}{R_{i j}}+m_{i} c_{p i} \frac{d T_{i}}{\mathrm{~d} t} \\
Q_{i}=\sum_{j, j \neq i}^{n} S_{i j} T_{j}+m_{i} c_{p i} \frac{d T_{i}}{\mathrm{~d} t} \\
\text { if } \quad i=j \quad S_{i i}=\sum_{k} \frac{1}{R_{i k}} \\
\text { if } \quad i \neq j \quad S_{i j}=-\sum_{k} \frac{1}{R_{i j}}
\end{gathered}
$$

Equation (30) is the basis used to solve the studied problem. It was applied for each node of the thermal network, $i$, whereas $j$ represents each node connected to $i$. In the steady-state case we have:

$$
\frac{d T_{i}}{\mathrm{~d} t}=0
$$

Hence, the equation can be stated as:

$$
Q_{i}-\sum S_{i j}\left(T_{i}-T_{j}\right)=0
$$

For all nodes we obtain a system of nonlinear equations, which is difficult to solve. Each node, $i$, generates a balance sheet of heat flux $\phi_{i j}$ giving us the system of equations which is non-linear. In this case we solve this system using the Newton-Raphson method [32]:

$$
\sum_{j} \phi_{i j}=0 \quad \text { for } \quad i=1 \ldots \ldots n
$$


For a series of nonlinear functions $q_{i}$, the NewtonRaphson method permits to have a system of simultaneous linear Equation (36). These equations can be solved for an error $\varepsilon_{j}$.

$$
\begin{gathered}
q_{i}+\sum_{j} \frac{\partial q_{i}}{\partial T_{j}} \varepsilon_{j}=0 \quad \text { for } \quad i=1 \ldots \ldots n \\
q_{i}=\sum_{j} \phi_{i j}=0 \quad \text { for } \quad i=1 \ldots \ldots n
\end{gathered}
$$

This non-linear equation can be solved by iteration. After initializing the parameters, each iteration is translated into a linear system equation (36) whose unknowns are the components of the error vector $\varepsilon_{j}$ between the corresponding temperatures of two successive iterations. The resolution is stopped when errors $\varepsilon_{j}$ are reasonably low.

In our case the system is composed by 21 nodes and we want to simulate the temperature evolutions in the ball bearing in steady state regime depending on the radial load, and the rotational velocity in different configurations. All thermal resistance values are calculated by given formulae developed before.

All heat dissipation sources are $Q_{1}$ corresponding to the node T3 (Inner ring/ball contacts), $Q_{2}$ corresponding to the node T5 (outer ring/ball contacts) and $Q_{3}$ defect temperature. This considered values are considered as inputs and calculated by the use of formulae developed in last section.

A computer program on Matlab software language was written to solve Equation (36) based on the theoretical model in steady state regime described in the last section. The temperature rise in the nodes and the heat generations under different operating parameters is calculated. Figure 5 illustrates the flow chart of the program to calculate the temperature distributions and heat generation in the ball bearing.

\section{Nodal distribution}

For the resolution we use the nodal method. The nodal model of the ball bearing consists of 21 nodes as shown in Table 1 and Figure 2. Two nodes are used to illustrate heat distribution in the loaded part of the outer ring (T6) as well as in the unloaded part (T9).

The discretization of the system components, ball bearing, shaft and housing is shown in Figure 8. On the shaft, are placed three volumetric nodes: (i) at the free end of the shaft, (ii) in middle, (iii) at the other end of the shaft. This modeling, coupled with that of the bearing obtained in a previous section, results in a $21 \times 21$ square system, whose resolution gives the temperature field in the bearing.

\section{Nodal distribution of generated heat flux due to the defect}

Energy, which evolves over time attributed to impacts of the rolling elements on the defect, and takes the form of

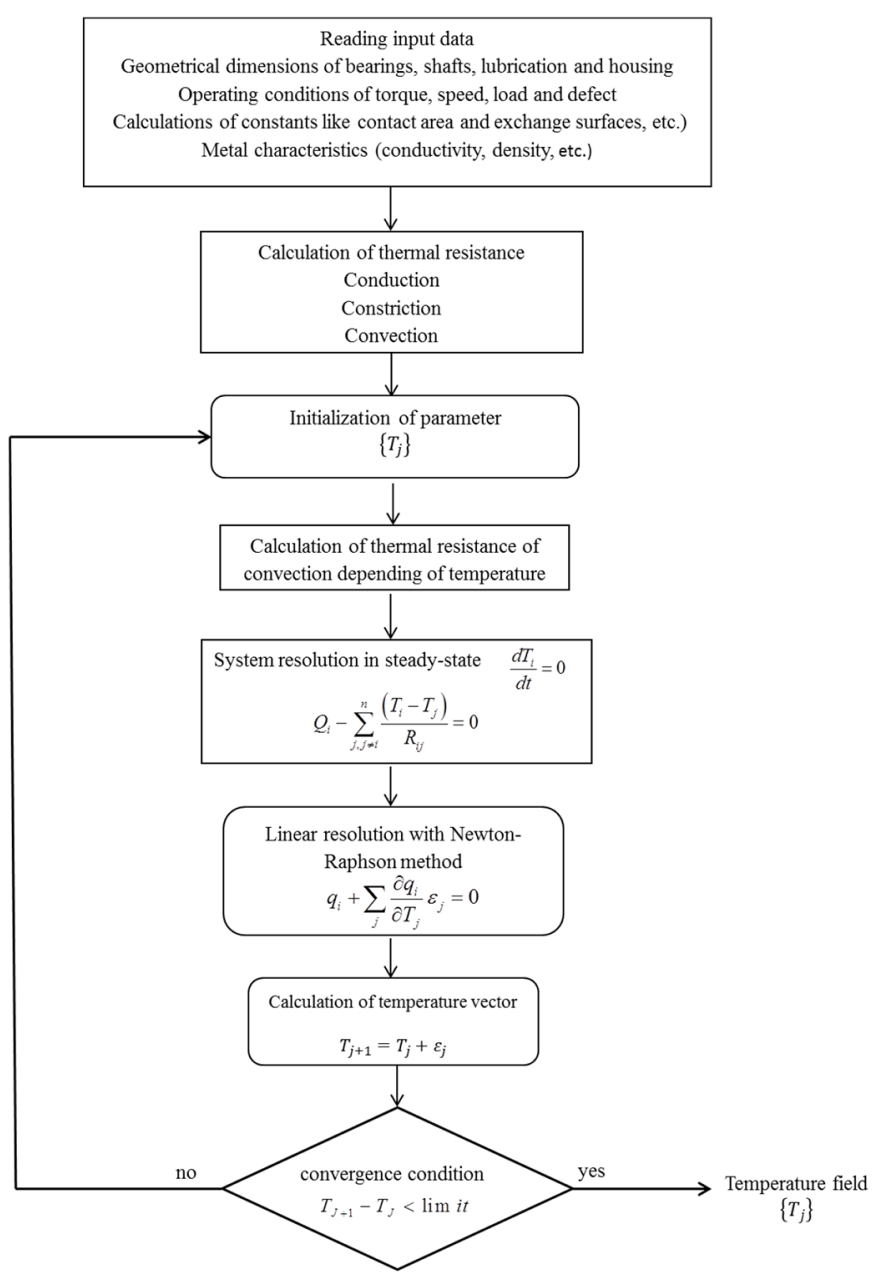

Fig. 5. Flow-chart for the algorithm of the resolution procedure.

heat flux, must be considered in the balance of heat energy in nodal modelling. Therefore, these connection nodes are added to a portion of the heat flux generated by successive impacts, as shown in Figure 6 .

These energies are distributed over connections of nodes between rolling elements and the defective ring. This distribution is proportional to the load distribution in the ball bearing. Consequently, the energy injected into each node depends not only on the number of nodes but also on their selected location during nodal discretization (see Fig. 7).

\section{Experimental investigations}

The study is focused on a rotating machine consisting on the use of ball bearings, type SKF 6206 to quantify energy intake linked to bearing defect localized on the outer rice. The test was carried out in two stages with healthy bearing, and then with a defect bearing of $17 \mathrm{~mm}^{2}$ of surface (Fig. 8). Lubrication is achieved by greasing of the two bearings, the bearings and grease properties are defined in Table 2. 
Table 1. Description of the nodes.

\begin{tabular}{ll}
\hline Node & Description \\
\hline T1 & Shaft/inner ring \\
T2 & Mass inner ring \\
T3 & Inner ring/ball contacts \\
T4 & Balls \\
T5 & Outer ring/balls contacts defect \\
T6 & Mass outer ring loaded part \\
T7 & Outer ring/housing loaded part \\
T8 & Outer ring/balls contacts without defect \\
T9 & Mass outer ring unloaded part \\
T10 & Outer ring/housing unloaded part \\
T11 & Outer ring/balls contacts \\
T12 & Mass outer ring \\
T13 & Outer ring/housing \\
T14 & Outer ring/balls contacts \\
T15 & Mass outer ring \\
T16 & Outer ring/balls contacts \\
T17 & Grease \\
T18 & At the free end of the shaft \\
T19 & In middle of the shaft \\
T20 & End of the shaft \\
T21 & Ambient air \\
\hline
\end{tabular}

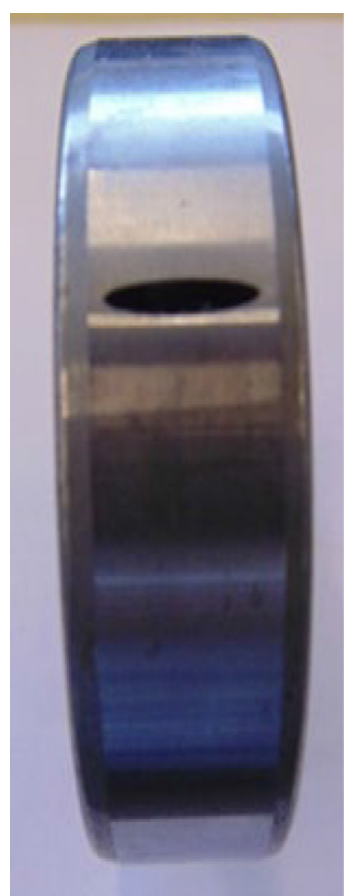

Fig. 8. Image of a defect on the ball bearing.

Table 2. Features of ball bearing and its grease.

\begin{tabular}{ll}
\hline Reference & SKF 6206 \\
\hline Pitch diameter & $46 \mathrm{~mm}$ \\
Balls diameters & $9.525 \mathrm{~mm}$ \\
Number of balls & 9 \\
Base oil viscosity $40{ }^{\circ} \mathrm{C}$ & $45 \mathrm{~mm}^{2} / \mathrm{s}$ \\
Density & $998 \mathrm{~kg} / \mathrm{m}^{3}$ \\
\hline
\end{tabular}

\subsection{Experimental setup}

A schematic illustration of the experimental setup is presented in Figure 9. An electric motor of $10 \mathrm{~kW}$ at variable speeds rotates the assembly system. The load carried by the hydraulic cylinder (Fig. 10) is considered to be radial.

For thermal measurements we need to know the value of emissivity, for that, the visible faces of the bearing are painted in black. The defective bearing is mounted in such a way that the defect is on the loaded portion to facilitate the visualization of the temperature rise. For thermal measurements, an infrared camera (CEDIP Titanium, $640 \times 512$ InSb detectors, with a pitch of $15 \mu \mathrm{m})$ is used to realize thermal maps of the outer ring, simultaneously submitted to rotation and radial loading. The used of $50 \mathrm{~mm}$ lens allows to obtain a spatial resolution compatible with the size of the region of interest, but also to be able to register simultaneously the temperature variations far from the system. This external ring is covered with black

Fig. 7. Schematic of energy intake of the impact. 


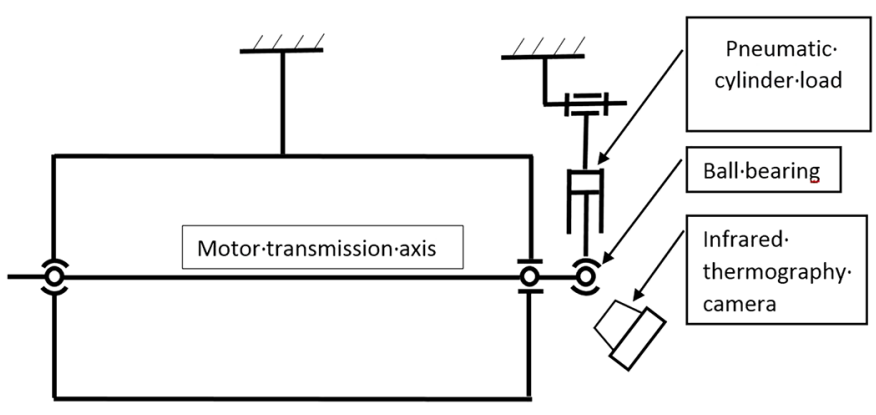

Fig. 9. Schematic illustration of the experimental setup.

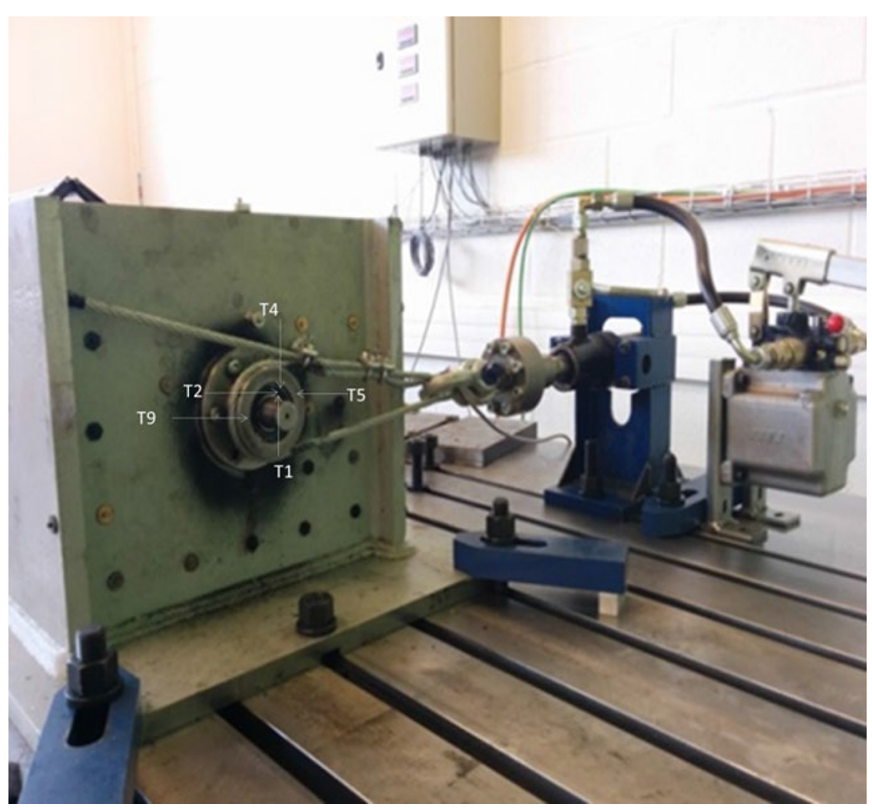

Fig. 10. Experimental setup image.

paint (emissivity equal to 0.92 ) in order to standardize and increase its uniformity, the stainless steel is well known to have a very low emissivity. Then, the adherence of the paint has to be regularly checked, because a local abruption would immediately change the measured signal in significant proportions. Due to the short distance between the object and the camera, the atmosphere is assumed to be transparent. However, a particular attention is paid to both uniformity and stability of the environment: choice of the device orientation relatively to the thermal sources, screening of the thermal parasites, and simultaneous recording of thermal reference points taken in the field of the camera. First of all, images are recorded at very low speed, until the thermal equilibrium is reached. This first step shows that the time constant of such system is of several tenths of minutes, due to the thermal inertia induced by the high mass of the metallic mechanical device. Once the thermal equilibrium is reached, a thermal sequence of 300 images is registered at $10 \mathrm{~Hz}$, and a mean image is computed in order to reduce the noise. Then, a small area is placed on the infrared image, at the aplomb of the defect. The thermal experimental values given in the present paper correspond to the average of this area. An example of thermogram obtained by infrared thermography is presented on Figure 11.

\section{Results and discussions}

\subsection{Results of bearing without defect}

This study examines the influence of rotational speed variations on the temperature distributions of a ball bearing. The obtained results from the simulation of increased temperatures in case of a ball bearing without defect, where the radial load is set at $500 \mathrm{~N}$ are shown in Figure 12. The temperature of different nodes of bearing increases when the rotational speed varies from $300 \mathrm{rpm}$ to $700 \mathrm{rpm}$ and the maximum value is measured at contact point located between the ball and the inner ring (node T3). The direction of the applied radial load affects strongly the temperature rise materialized by nodes $\mathrm{T} 2, \mathrm{~T} 4$ and then T5. This increase of heat flux in the contact zone is due, first, to the stress applied by the load and, second, to the phenomenon of constriction of the heat flux. In Figure 13, the temperature of the loaded part increases greatly whereas the unloaded part exhibits no such behavior; this shows the effect of the applied load direction on the temperature of the bearing parts. Figure 14 compares the generated heat (at node T5) obtained from both the numerical and experimental results. Both results show that the heat generated by node $\mathrm{T} 5$ increases with the increase of the rotation speed and exhibit the same trend.

Figure 15 presents the predicted results of the increase of the temperature as a function of the variation of the radial load. The increase of temperature is found to be proportional to the increase of the applied radial load in a non-linear relationship with a maximum value measured at contact point between the ball and the inner ring (node T3). The direction of the applied radial load affects strongly the increase in temperature of the bearing as shown in Figure 16. In Figure 17 we present a comparison between the numerical and the experimental results of heat generated at (node T5) of ball bearing without a defect as it depends on the variation of the load. As we can see, the result show that the two curves have a similar pattern when the radial load increases, although a very small difference caused by the parasite temperature of the surrounding system can be observed.

\subsection{Ball bearing with defect}

Damaged ball bearing refers to a ball bearing with a defect of $17 \mathrm{~mm}^{2}$ located on its outer ring. As illustrated in Figure 18, we present the evolution of the temperature of node $\mathrm{T} 5$ obtained by the numerical and the experimental measurements realized by the infrared camera. The results are given under radial load equal to $500 \mathrm{~N}$. Figure 18 shows that both curves have the same pattern; the temperature increases with the increase of rotational speed. With a varying of the applied radial load where the force maintained in a fixed direction, both numerical and 

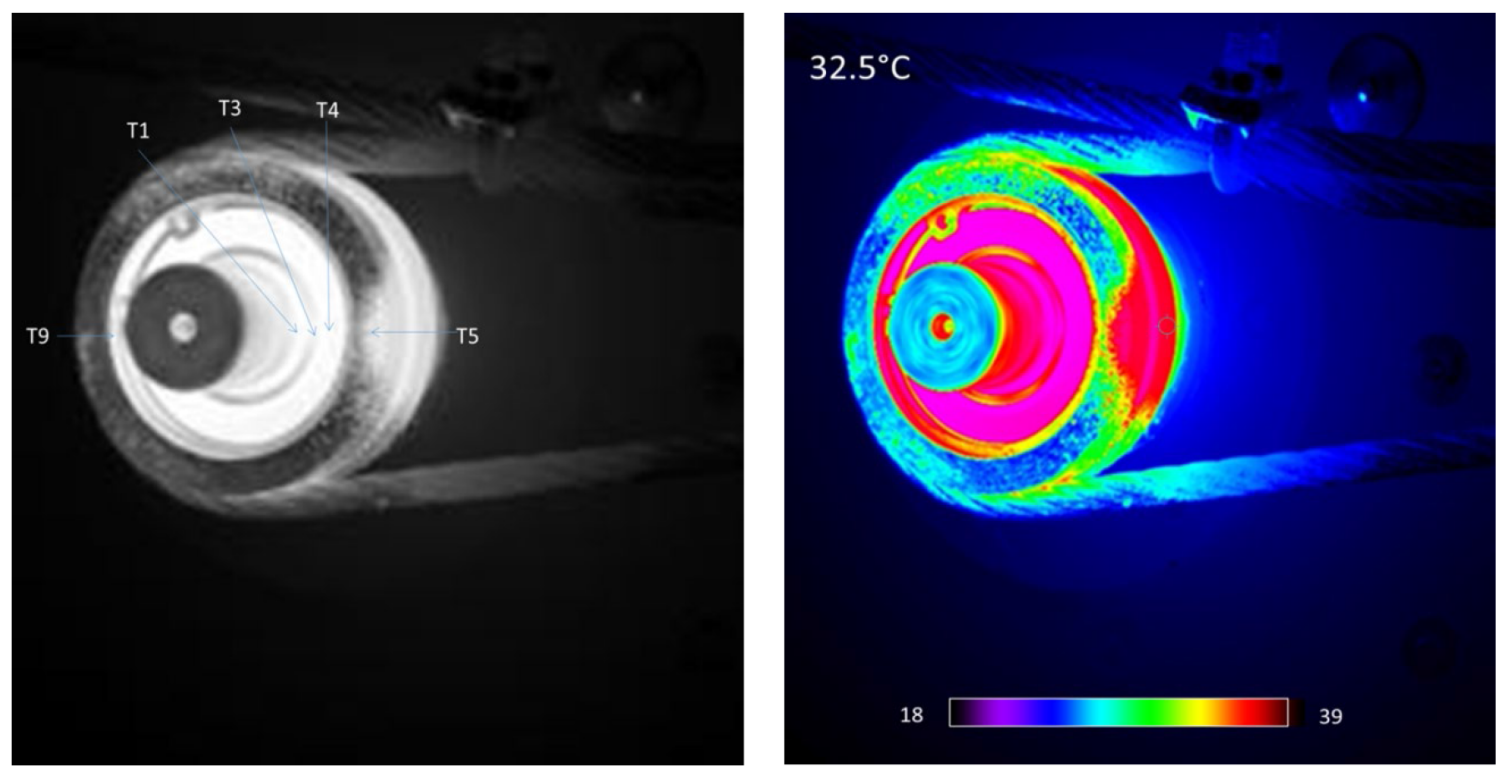

Fig. 11. Experimental Infrared thermogram obtained by infrared camera CEDIP.

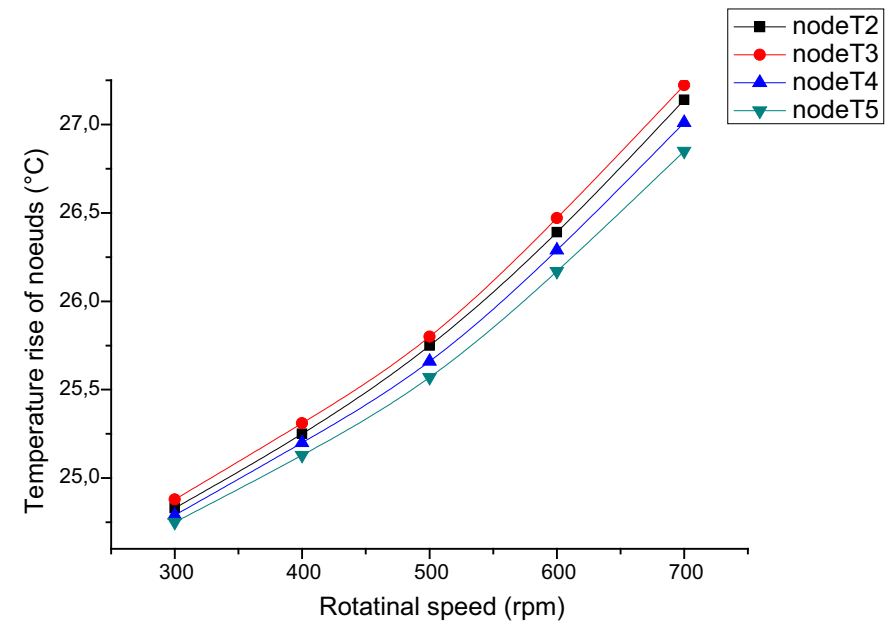

Fig. 12. Rotational speed effect on temperature rise of the bearing.

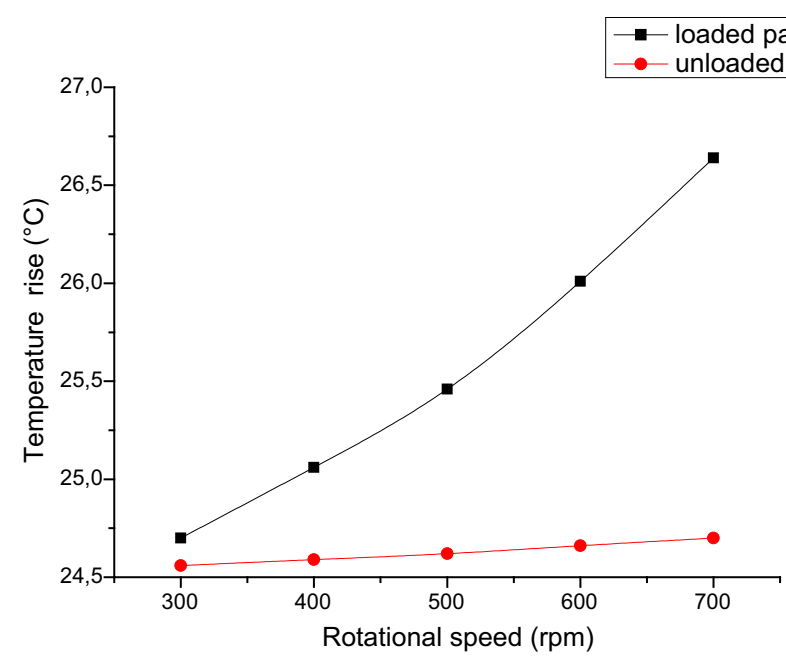

Fig. 13. Temperature evolution with rotational speed of the loaded and unloaded parts.

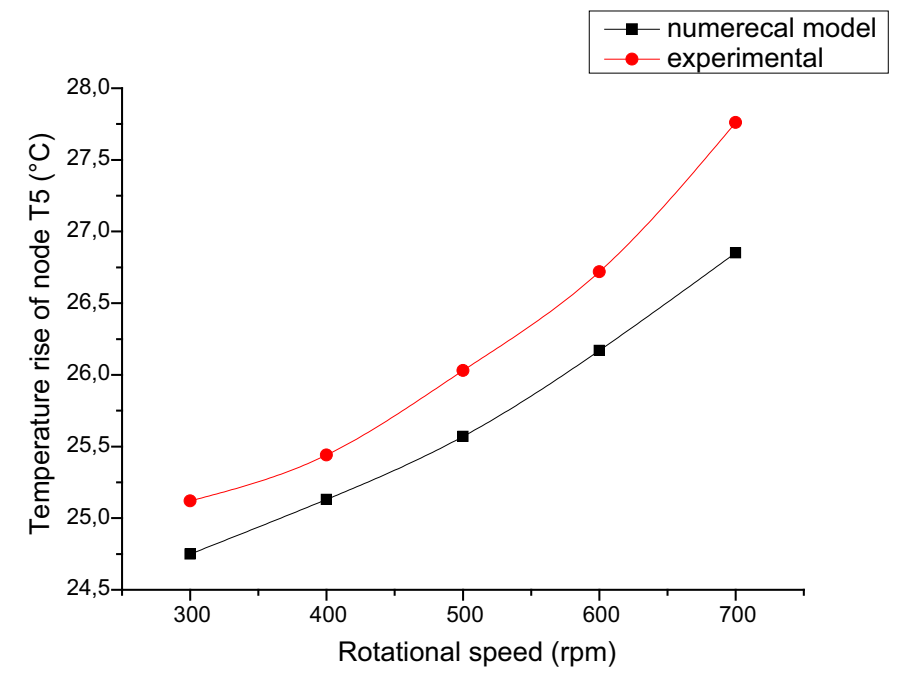

Fig. 14. Numerical and experimental comparison of temperature of node $\mathrm{T} 5$ with variation of the rotational speed.

experimental with a defect are compared. In Figure 19 we show that as the radial load increases the temperature in the bearing increases as well. Both curves have the same evolution and both results demonstrate the validation of the model to predict temperature increases with a localized defect on the bearing.

In Figure 20, we present a comparison of the temperature evolutions in between the loaded and unloaded parts for a ball bearing with a defect. We notices that the increase in rotation speed affects considerably the temperature rise in the loaded part. It can be noted that the presence of a defect in the bearing contributes considerably to this increase. The same results are observed in Figure 21, where the application of a radial load on the defective bearing results in a drastic temperature rise compared to that of the bearing without defect. 


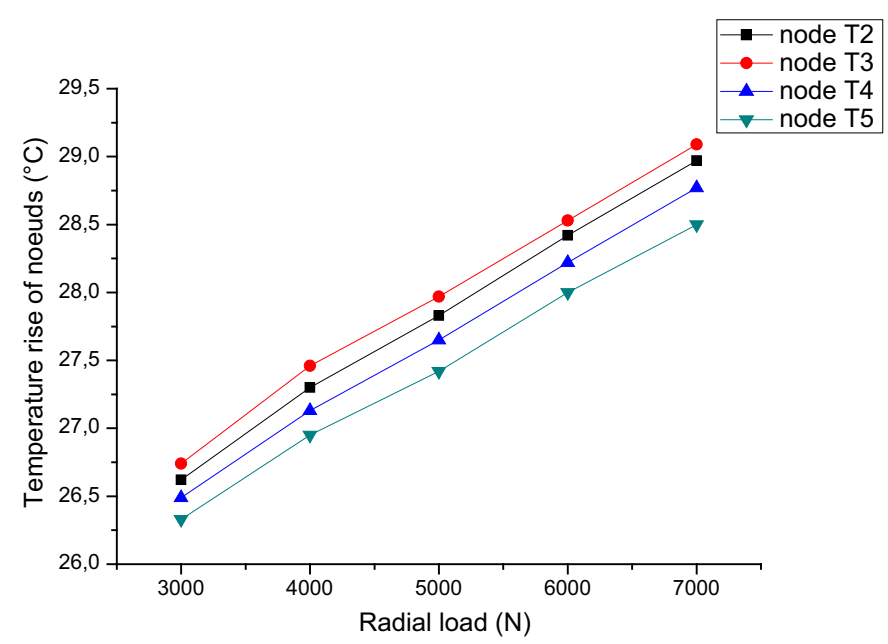

Fig. 15. Radial load effect on temperature rise.

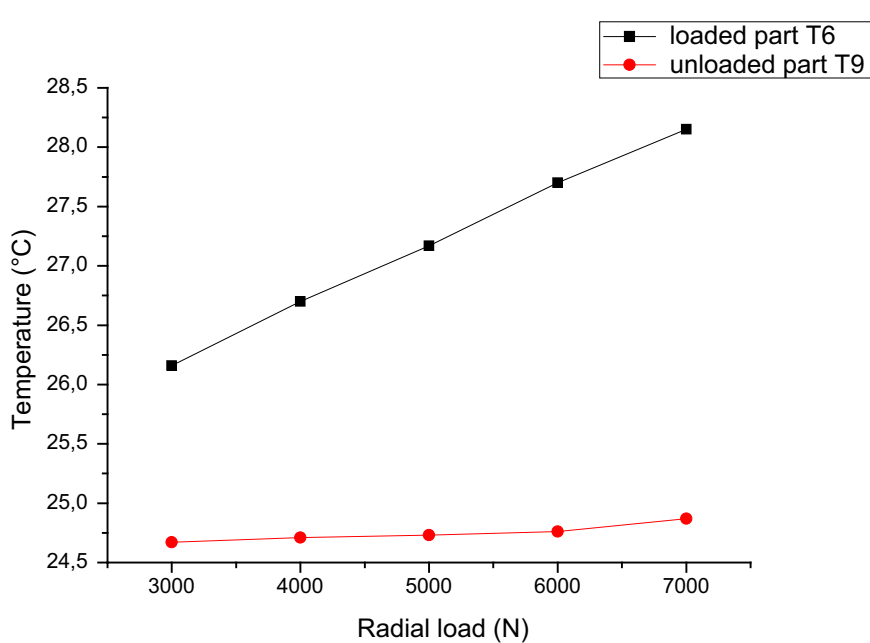

Fig. 16. Influence of the radial load variations on the temperature rises of the loaded and unloaded parts.

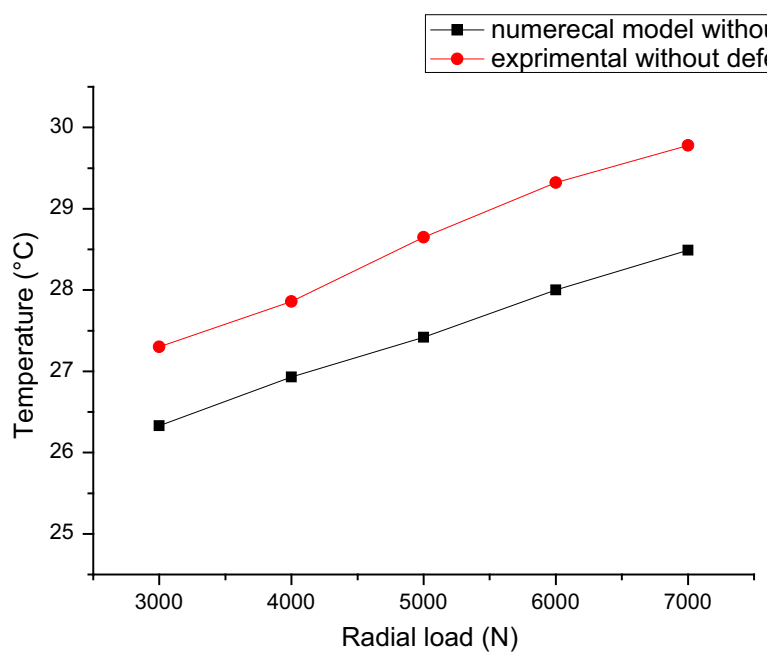

Fig. 17. Comparison between numerical and experimental results of temperature rise of node $\mathrm{T} 5$ as a function of radial load.

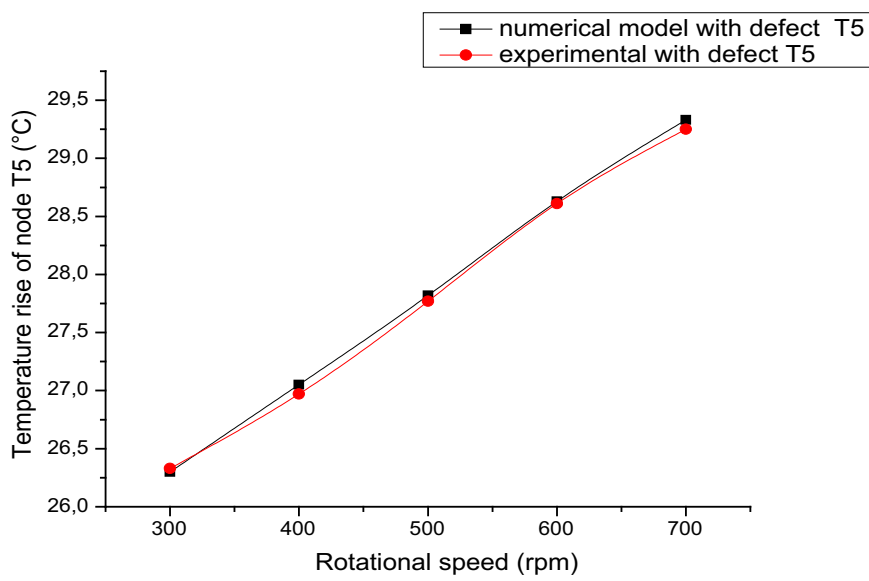

Fig. 18. Comparison between numerical and experimental results of temperature rise of node $\mathrm{T} 5$ as a function of rotational speed for the damaged ball bearing.

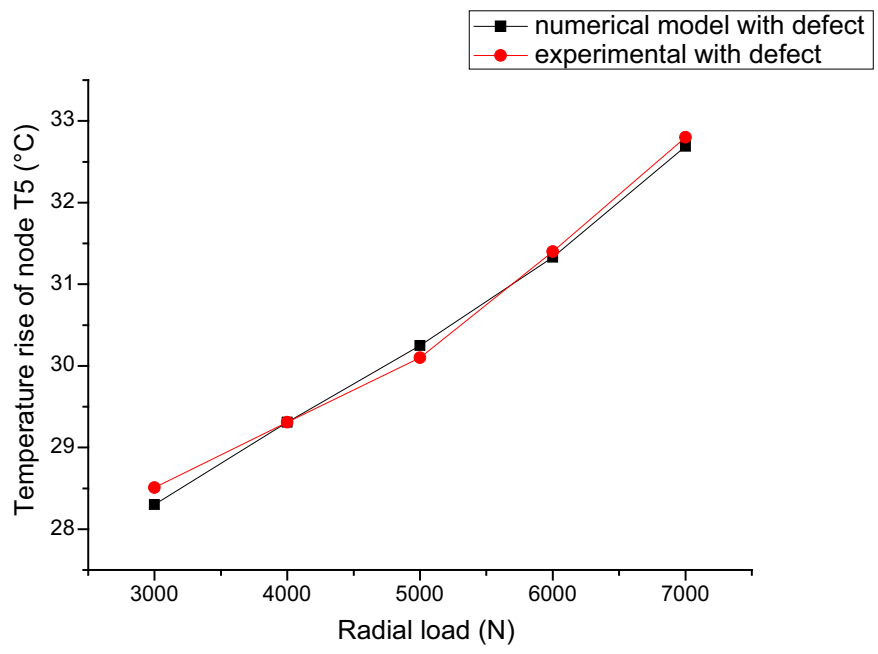

Fig. 19. Comparison between numerical and experimental results of temperature rise of node $\mathrm{T} 5$ as a function of radial load for the damaged ball bearing.

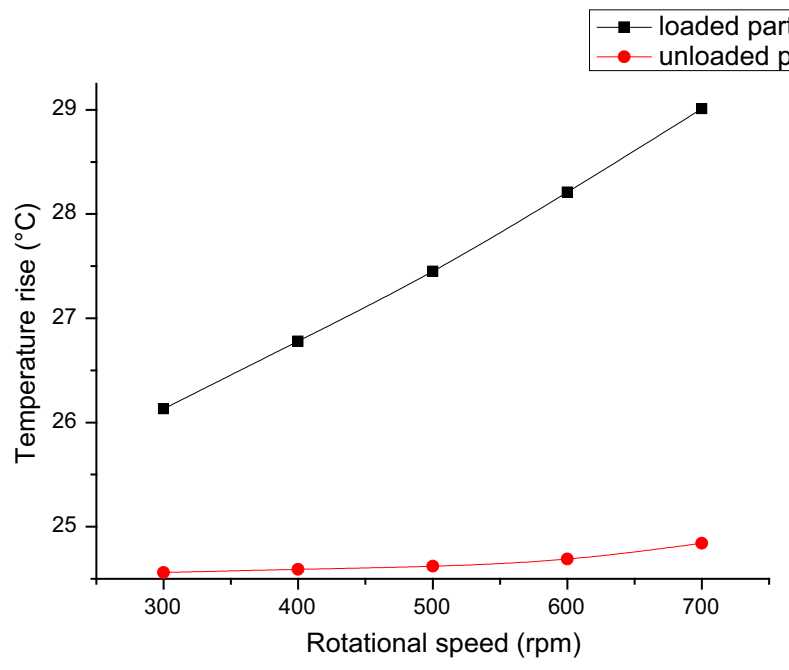

Fig. 20. Comparison of temperature evolution as a function of rotational speed between the loaded and unloaded parts for the damaged ball bearing. 


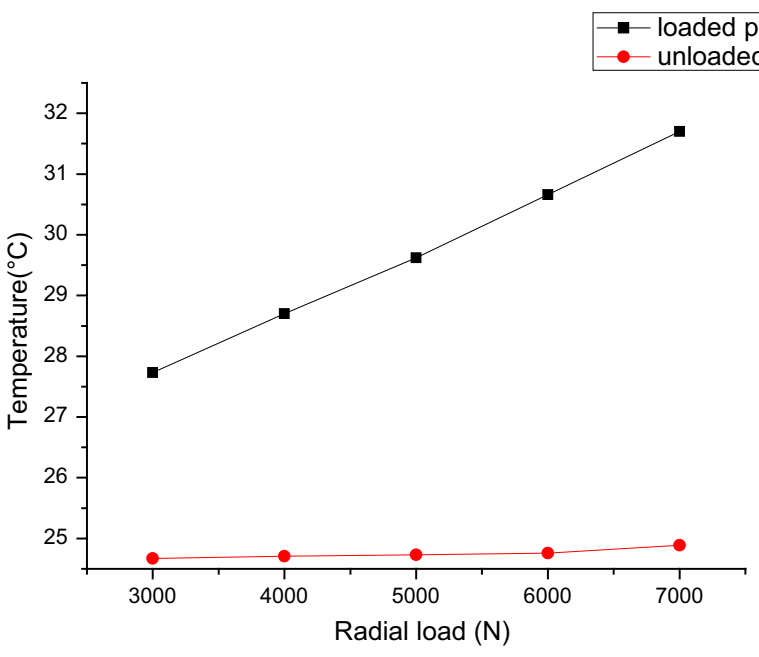

Fig. 21. Temperature evolution as a function of radial load between the loaded and unloaded parts for the damaged ball bearing.

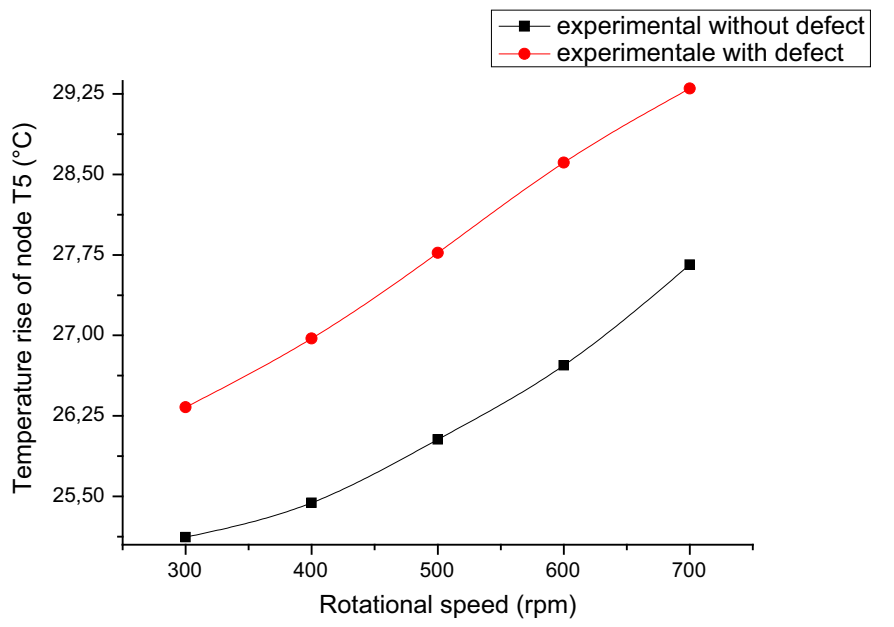

Fig. 22. Experimental temperature rise of node T5 results as a function of rotational speed of a damaged and healthy ball bearing.

In Figure 22, we compare the results obtained from experimental tests: two ball bearings with and without defect. Both temperature curves increase with increasing rotational speed and exhibit the same pattern. Moreover, in a defective ball bearing, the temperature rise is considerably higher than that in a bearing without defect, which shows that our theory is founded. Another comparison of temperature evolution obtained from experimental tests on the two ball bearings, with and without defect, depends on the radial load as shown in Figure 23. Indeed, it can be seen that with increasing radial load, the dissipated heat increases as well. At high load value, the effect of the thermal response on the dynamic system is significant.

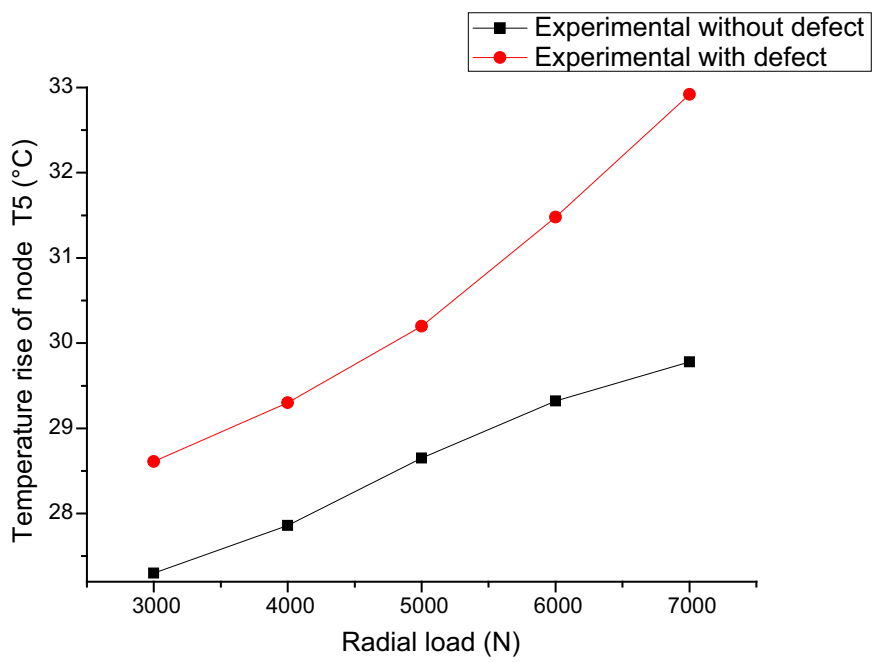

Fig. 23. Comparison of the temperature rise of node $\mathrm{T} 5$ as a function of radial load between the damaged and healthy ball bearings.

\section{Conclusion}

A well-maintained production equipment is necessary for both safety and production concerns and requires accurate and effective damage detection techniques and procedures. This study reported on the thermal analysis of defected or not defected bearings. A model validated by an experiment was developed to predict heat distribution in the bearings and quantify the severity of the defect or damage through temperature increases. The model is based on the nodal theory and incorporates a defect on the outer ring of the bearing. The experiment was performed on a housing made of two ball bearings and resulted in a temperature of the damaged bearing higher than that of the good one. In addition, the temperature at the loaded part of the ball bearing was higher than that of the unloaded part. These experimental results concur with the model's ones. The model quantified the severity of defects appearing on the bearings with a good efficiency depending on the conditions of use of the system. As we have seen, the developed model also allows to analyses the influence of operating conditions on a ball bearing without defect.

\section{Nomenclature}

a Half-elliptical radius in the rolling direction (m)

A Exchange surface $\left(\mathrm{m}^{2}\right)$

$b \quad$ Half-elliptical radius in the direction transverse to the rolling $(\mathrm{m})$

$C p \quad$ Specific heat $(\mathrm{J} / \mathrm{kg} . \mathrm{K})$

$d \quad$ Diameter of the rolling element $(\mathrm{m})$

$D \quad$ Diameter of the bearing ball $(\mathrm{m})$

$D_{h} \quad$ Diameter of the outer ring or housing of the ball bearing $(\mathrm{m})$

$f_{0} \quad$ The factor depending upon type of bearing and lubrication system (dimensionless)

$F_{m} \quad$ The force exerted by a rolling element on the singularity $(\mathrm{N})$ 
$F_{r} \quad$ Radial force $(\mathrm{N})$

$h_{v} \quad$ Convective heat transfer coefficient $\left(\mathrm{W} / \mathrm{m}^{2} \cdot{ }^{\circ} \mathrm{C}\right)$

$K \quad$ Thermal conductivity $\left(\mathrm{W} / \mathrm{m} .{ }^{\circ} \mathrm{C}\right)$

$L \quad$ Bearing length $(\mathrm{m})$

$d_{\text {ext }} \quad$ Outer ring diameter $(\mathrm{m})$

$d_{\text {int }} \quad$ Inner ring diameter $(\mathrm{m})$

$M_{\text {frot }}$ Torque acting on the ball bearing (N.m)

$M_{l} \quad$ Friction torque due to applied load (N.m)

$M_{v} \quad$ Viscous friction torque (N.m)

$M_{f} \quad$ Friction torque due to flange load (N.m)

$F_{\beta} \quad$ Dynamical equivalent load (N)

$Q_{\text {roul }}$ Bearing frictional power loss $(\mathrm{W})$

$\omega_{\text {roul }}$ Rotational speed (rev/min)

$v \quad$ Kinematic viscosity of lubricant $\left(\mathrm{m}^{2} / \mathrm{s}\right)$

$\alpha \quad$ Thermal diffusivity $\left(\mathrm{m}^{2} / \mathrm{s}\right)$

$\mathrm{Pe} \quad$ Peclet number (dimensionless)

$N_{u} \quad$ Nusselt number (dimensionless)

$R_{t h k} \quad$ Thermal resistance of conduction

$R_{t h} \quad$ Thermal resistance of constriction $\left({ }^{\circ} \mathrm{C} / \mathrm{W}\right)$

$R_{t h V}$ Thermal resistance of convection

$T$ Temperature $\left({ }^{\circ} \mathrm{C}\right)$

$T_{a} \quad$ Ambient Temperature $\left({ }^{\circ} \mathrm{C}\right)$

$S \quad$ Area of outer ring $\left(\mathrm{m}^{2}\right)$

$W_{h} \quad$ Width of the outer ring of the ball bearing $(\mathrm{m})$

$V_{c} \quad$ Relative velocity of the cage $(\mathrm{m} / \mathrm{s})$

$V \quad$ Relative velocity of contact $(\mathrm{m} / \mathrm{s})$

$\gamma_{\text {air }} \quad$ Kinematic viscosity of air $\left(\mathrm{m}^{2} / \mathrm{s}\right)$

$\chi \quad$ Thermal effusivity $\left(\mathrm{J} . \mathrm{K}^{-1} \cdot \mathrm{m}^{-2} \cdot \mathrm{s}^{-1 / 2}\right.$ )

Re Reynolds number (dimensionless)

Pr Prandtl number (dimensionless)

$f_{l} \quad$ Factor depending upon bearing design (dimensionless)

$d_{m} \quad$ Pitch diameter $(\mathrm{m})$

$V_{c b} \quad$ Normal velocity of the ball $(\mathrm{m} / \mathrm{s})$

$\Delta T_{s} \quad$ Shock period (s)

$T_{d o} \quad$ Periodicity of the passage of rolling elements upon the outer ring defect $(\mathrm{s})$

$D_{1} \quad$ Distance between the middle of two balls $(\mathrm{m})$

$r_{m} \quad$ Mean radius of the bearing $(\mathrm{m})$

$Z \quad$ Number of rolling elements (dimensionless)

$f_{a b} \quad$ The passing frequency of rolling element on outer ring defect $\left(\mathrm{s}^{-1}\right)$

$f_{r} \quad$ The rotational frequency of the inner $\operatorname{ring}\left(\mathrm{s}^{-1}\right)$

$P_{s} \quad$ Power of shock (W)

$Q_{\max }$ Ball load under radial load or Stribeck load (N)

$S_{d} \quad$ Surface defect $\left(\mathrm{m}^{2}\right)$

$t \quad$ Time $(\mathrm{s})$

$Q \quad$ Generated heat rate $(\mathrm{W})$

$U \quad$ Internal energy $(\mathrm{J})$

$Z \quad$ Number of rolling elements (balls)

$R_{i j} \quad$ Thermal resistance between nodes i and j $\left({ }^{\circ} \mathrm{C} / \mathrm{W}\right)$

$S_{i j} \quad$ Thermal conductance between nodes i and $\mathrm{j}\left(\mathrm{W} /{ }^{\circ} \mathrm{C}\right)$

$m_{i} \quad$ Mass at node $\mathrm{i}(\mathrm{kg})$

$\mathrm{Cp}, i \quad$ Specific heat of node i $\left(\mathrm{J} / \mathrm{kg} .{ }^{\circ} \mathrm{C}\right)$

$Q_{i} \quad$ Heat transfer rate by the node i $(\mathrm{W})$

$\varphi_{i j} \quad$ Energy flows exchanged between two nodes $\mathrm{i}$ and $\mathrm{j}$ (W)

$q_{i} \quad$ Heat flux $\left(\mathrm{W} / \mathrm{m}^{2}\right)$

$\varepsilon_{j} \quad$ Error vector $\left({ }^{\circ} \mathrm{C}\right)$ $n \quad$ Total number of nodes (dimensionless)

$\Psi_{d o} \quad$ Incident surface flux $\left(\mathrm{W} / \mathrm{m}^{2}\right)$

$\alpha \quad$ Contact angle

$\Psi_{j} \quad$ The energy of node $\mathrm{j}(\mathrm{W})$

\section{References}

[1] A. Fasana, S. Marchesiello, M. Pirra, L. Garibaldi, A. Torri, Spectral Kurtosis against SVM for best frequency selection in bearing diagnostics, Mecanique \& Industry 11, 489-494 (2010)

[2] M. Kedadouche, M. Thomas, A. Tahan, Cyclostationarity applied to acoustic emission and development of a new indicator for monitoring bearing defects, Mechanics \& Industry 15, 467-476 (2014)

[3] K. Ait Sghir, F. Bolaers, O. Cousinard, J. P. Dron, Vibratory monitoring of a spalling bearing defect in variable speed regime, Mechanics \& Industry 14, 129-136 (2013)

[4] O. Djebili, F. Bolaers, A. Laggoun, J. P. Dron, Following the growth of a rolling fatigue spalling for predictive maintenance, Mechanics \& Industry 14, 85-93 (2013)

[5] A. Bejan, Theory of rolling contact heat transfer, J of Heat Transfer 2, 257-263 (1989)

[6] R. Holm, Calculation of the temperature development in a heated contact with appreciation to sliding contacts, Journal of Applied Mechanics 19, 369 (1947)

[7] Y.L. Chow, M.M. Yovanovich, The shape factor of the capacitance of a conductor, Journal of Applied Physics 53, 8470-8475 (1982)

[8] T.F. Lemczyk, M.M. Yovanovich, Thermal constriction resistance with convective boundary conditions. Half-space contacts, II - Layered half-space contacts, International Journal of Heat and Mass Transfer 9, 1861-1872 (1988)

[9] A.B. Jones, Ball motion and sliding friction in ball bearings, ASME, J. Basic Eng 81, 1-12 (1959)

[10] T.A. Harris, Rolling Bearing Analysis, 4th Edition, John Wiley and Sons, 2001

[11] N.T. Liao, J.F. Lin, Rolling-Sliding Analysis in Ball Bearing Considering Thermal Effect, Trib. Trans 1, 1-16 (2015)

[12] H.J. Böhmer, T. Lösche, F.J. Ebert, E. Streit, The influence of heat generation in the contact zone on bearing fatigue behaviour, Journal of tribology 3, 462-467 (1999)

[13] Y. Muzychka, M. Yovanovitch, Thermal resistance models for non circular moving heat sources on a half space, Transaction of the ASME, Journal of Heat Transfer 3, 624-632 (2001)

[14] H. Blok, The flash temperature concept, Journal of Wear 6 , 483-494 (1963)

[15] A. Bä̈ri, N. Alilat, J.G. Bauzin, N. Laraqui, Three dimensional stationary thermal behavior of a bearing ball, International Journal of Thermal Sciences 6, 561-568 (2004)

[16] F. Pouly, C. Changenet, F. Ville, P. Velex, B. Damiens, Power loss predictions in high speed rolling element bearings using thermal networks, Trib. Trans 6, 957-967 (2010)

[17] K. Yan, Y.T. Wang, Y.S. Zhu, Investigation on heat dissipation characteristic of ball bearing cage and inside cavity at ultra-high rotation speed, Trib. Int 93, 470-481 (2016) 
[18] J. Takabi, M.M. Khonsari, Experimental testing and thermal analysis of ball bearings, Trib. Int 60, 93-103 (2013)

[19] A. Neurouth, C. Changenet, F. Ville, A. Arnaudon, Thermal modeling of a grease lubricated thrust ball bearing, J. Engineering Tribology 11, 1266-1275 (2014)

[20] J. Takabi, M.M. Khonsari, On the thermally-induced failure of rolling element bearings, Trib. Int 94, 661-674 (2016)

[21] J. Takabi, M.M. Khonsari, On the thermally-induced seizure in bearings: A review, Trib. Int 91, 118-130 (2015)

[22] A. Neurouth, C. Changenet, F. Ville, M. Octrue, Influence of rolling element bearing modeling on the predicted thermal behavior of the FZG test rig. Tribology Transactions, 60, 753-761 (2017)

[23] K. Yan, J. Hong, J.H. Zhang, Thermal-deformation coupling in thermal network for transient analysis of spindle-bearing system, International Journal of Thermal Sciences 104, 1-12 (2016)

[24] D. Zheng, W. Chen, Thermal performances on angular contact ball of high-speed spindle considering structural under oil-air lubrication, Trib. Int 109, 593-601 (2017)

[25] F. Pouly, C. Changenet, F. Ville, P. Velex, B. Damiens, Investigation on the power losses and thermal behaviour of rolling element bearings, Proceeding of the Institution of
Mechanical Engineers, Part J: Journal of Engineering Tribology 224, 925-933 (2010)

[26] Y.R. Jeng, P.Y. Huang, Prediction of temperature rise for ball bearings, Journal of Tribology Transaction 1, 49-56 (2003)

[27] A. Palmgren, Ball and Roller Bearing Engineering, 3rd edn., SKF Industries, Inc., Burbank, Philadelphia, 1959, 34-41

[28] C. Wagner, Heat transfer from a rotating disk in ambient air, Journal of Applied Physics 9, 837-839 (1948)

[29] N. Tandon, A. Choudhury, An analytical model for the prediction of the vibration response of rolling element bearings due to localized defect, Journal of Sound and Vibration 3, 275-292 (1997)

[30] F. Bogard, Y.K. Debra, Y.Q. Guo, Determination of sensor position for predictive maintenance of revolving machines, International Journal of Solids and Structures 12, 3159-3173 (2002)

[31] C. Changenet, X. Oviedo-Marlot, P. Velex, Power loss predictions in geared transmissions using thermal networks applications to a six speed manual gear box, Transactions of the ASME, Journal of Mechanical Design 128, 618-625 (2006)

[32] G.A. Korn, T.M. Korn, Mathematical Handbook for Scientists and Engineers, Mc-Graw-Hill, New York, 1968

Cite this article as: D. Belmiloud, M. Lachi, H. Pron, F. Bolaers, J.-P. Dron, X. Chiementin, A. Laggoun, Thermo-dynamical modelisation of the degradation of a ball bearing in variables use conditions, Mechanics \& Industry 21, 608 (2020) 